\title{
OMENIEN PUTOAMISEN VÄHENTÄMISESTÄ ENNEN SADONKORJUUTA JA SEN AIKANA
}

\author{
ЈААККо SӓKÖ \\ Putarhantutkimuslaitos, Piikkiö
}

Saapunut 30. 10. 1958

Hedelmänviljelijät tuntevat hyvin sen haitan, jonka omenien putoaminen vähän ennen sadonkorjuuta tai sen aikana aiheuttaa. Vuosittain siitä koituu huomattavia tappioita. Omenien putoamiseen vähän ennen kuin ne ovat saavuttaneet korjuukypsyyden tai korjuukauden jo ollessa käsillä ovat erityisesti taipuvaisia aikaisin kypsyvät kesälajikkeet, mutta se on yleistä myös monilla syys- ja eräillä talvilajikkeillakin. Putoaminen ei kuitenkaan ole riippuvainen yksinomaan lajikeominaisuuksista, vaan myös korjuuajan ja sitä edeltävistä sääoloista, erityisesti voimakkaista tuulista. Edelleen ovat siihen vaikuttamassa kasvupaikan olosuhteet ja hedelmätarhan hoito. Niinpä esimerkiksi käytettäessä nurmikompostia omenapuiden kasvualustana omenien putoaminen ei ole lainkaan niin yleistä kuin mullosmaassa kasvavissa puissa. Tämä johtuu ilmeisesti siitä, että kasvualustan kosteusolot ensiksi mainittua menetelmää käytettäessä eivät vaihtele niin paljon kuin mullosmaassa.

LUCKWILl (8) on osoittanut, että omenien niin hyvin kuin omenaraakileidenkin putoaminen seuraa siementen auksiinipitoisuudessa tapahtuvia muutoksia. Putoamista esiintyy silloin kun siementen auksiinipitoisuus on pieni. Auksiinipitoisuuden kasvaessa taas omenien putoaminen vähenee. Ensimmäinen hedelmien raakileiden putoaminen tapahtuu kahden - kolmen viikon aikana kukkien terälehtien putoamisesta, jolloin auksiinia ei esiinny nuorissa siemenissä. Toinen putoamisvaihe ns. "June drop", joka meidän oloissamme tapahtuu tavallisesti heinäkuussa, seuraa verrattain pian ensimmäistä. Tällöin alkio kasvaa nopeasti, jolloin auksiinia muodostavan siemenvalkuaisen suhteellinen määrä vähenee siemenissä. Kolmas putoamisvaihe alkaa silloin kun omenat saavuttavat korjuukypsyyden. Alkio on silloin täydellisesti kehittynyt, ja siementen auksiinipitoisuus vähenee. Tästä voi olla seurauksena verraten nopea hedelmien putoaminen, mikä on luonteenomaista mm. Filippa-lajikkeelle. Useimpien lajikkeiden hedelmien putoaminen tapahtuu 
kuitenkin asteittain. On myös lajikkeita, joiden omenat pysyvät puussa hyvin kiinni korjuukypsyyden saavutettuaankin. Tällaisia ovat mm. maassamme vakiolajikkeina viljellyt Huvitus ja Lobo.

Melkoista huomiota herättivät yhdysvaltalaisen GARDNERin ym. (6) v. 1939 suorittamat tutkimukset, jotka osoittivat, että ruiskuttamalla tiettyjä kasvuaineita omenapuihin vähän ennen kuin omenat saavuttavat korjuukypsyyden voidaan omenien putoamista vähentää. Heidän kokeilemistaan aineista osoittautui $\alpha$-naftatyylietikkahappo parhaimmaksi. Tämän aineen verrattain laimeat liuokset $(10-25 \mathrm{ppm})$ antoivat hyvän tuloksen. Tälle tutkimukselle antoivat aiheen pistokaslisäyksessä tehdyt havainnot kasvuhormoonien käytöstä. Näiden aineiden nimittäin todettiin myöhästyttävän lehtien kantojen irtaantumista pistokkaista. Vastaavasti havaittiin niiden hidastavan omenan kannan irtaantumisvyöhykkeen (engl. abscission layer) muodostumista.

Tämän jälkeen on $\alpha$-naftyylietikkahappoa käytetty laajalti amerikkalaisissa hedelmätarhoissa viivästyttämään omenien putoamista. Sen vaikutus tähän tarkoitukseen on todettu kuitenkin verraten lyhytaikaiseksi sekä riippuvaiseksi ulkoisista tekijöistä, kuten lämpötilasta ja omenapuun kasvukunnosta (4). Edelleen on sen tehokkuus ollut erilainen eri omenalajikkeihin. Samanlaiseen tulokseen johti myös 2,4-diklorfenoksietikkahapon kokeileminen omenien putoamisen ehkäisemiseksi $(1,2)$. Sekin osoittautui olevan erittäin käyttökelpoinen muutamille lajikkeille, mutta sen sijaan tehoton toisiin lajikkeisiin.

V. 1949 totesivat EDGERTon ja Hoffman (4), että 2,4,5-triklorfenoksipropionihappoa (2,4,5-TP) voidaan menestyksellä käyttää McIntosh-lajikkeen omenien putoamisen ehkäisemiseksi. Sen teho osoittautui huomattavasti pitempiaikaiseksi kuin $\alpha$-naftyylietikkahapon. Samalla sen käyttö lisäsi omenien punaista väriä. Myöhemmin 2,4,5-TP:llä järjestetyt kokeet $(3,5,10,11,12)$ osoittivat, ettei ko. aine ollut lajikkeisiin nähden selektiivinen, kuten edellä mainitut aineet, vaan tehosi hyvin useihin omenalajikkeisiin. Ruiskutusnesteen sopivaksi väkevyydeksi katsottiin $20 \mathrm{ppm}$ käytettäessä paineruiskua. Sen sijaan sumuruiskulla ruiskutettaessa osoittautui $60-80 \mathrm{ppm}$ :n väkevyys sopivaksi. Edelleen on todettu, että 2,4,5-TP edistää omenien kypsymistä, mikä ilmeni kuitenkin vain kysymyksen ollessa aikaisista kesäomenista. Syys- ja talviomeniin ei sillä ole todettu olevan tällaista vaikutusta $(9,12)$.

Seuraavassa esitetään Suomessa tehtyjä kokeita 2,4,5-TP:n käytöstä omenien putoamisen vähentämiseksi.

\section{Kokeiden järjestely}

Puutarhantutkimuslaitoksella tehtiin v. 1958 kokeita, joissa selvitettiin 2,4,5TP:n vaikutusta eräiden omenalajikkeiden putoamiseen ennen sadonkorjuuta. Kokeet järjestettiin osaksi laitoksen omassa hedelmätarhassa sekä osaksi Spurilan hedelmätarhassa Paimiossa. Mukana oli seitsemän omenapuulajiketta, nimittäin Bergius, Sävstaholm, Melba, Atlas, Wealthy, Åkerö ja Antonovka. Kolmelle ensiksi mainitulle lajikkeelle suoritettiin ruiskutus 21 päivää, Atlas-, Wealthy- ja Åkerö- 
puille 24 päivää ja Antonovka-puille 33 päivää ennen sadonkorjuuta. Kokeeseen valittiin kustakin lajikkeesta puut, jotka olivat samanikäisiä, ja joiden sadot näyttivät muodostuvan suunnilleen samansuuruisiksi. Pudonneet omenat kerättiin ja punnittiin määräpäivinä.

Käytettäessä paineruiskua (Ginge) oli 2,4,5-TP-liuoksen väkevyys 20 ppm. Sumuruiskulla ruiskutettaessa nostettiin väkevyys $80 \mathrm{ppm}$ :an. 2,4,5-TP, joka on veteen melko hitaasti liukeneva, liuotettiin ensin pieneen määrään etyylialkoholia.

Eräiden koejäsenien kohdalla lisättiin ruiskutusnesteeseen Tween 20-valmistetta (polyoksietyleeni sorbitan monolauraatti, valmistaja: Atlas Powder Co., Wilmington, Delaware). Tämän aineen, jolla on kukinnan jälkeen käytettynä lievä vaikutus omenien raakileiden harvennusruiskutuksissa (7), todettiin v. 1958 Puutarhantutkimuslaitoksella järjestetyissä raakileenharvennuskokeissa myös lisäävän $\alpha$-naftyylietikkahapon tehoa. Tämä perustuu sen ruiskutusnesteen pintajännitystä pienentävään vaikutukseen. Tässä tapauksessa pyrittiin selvittämään, parantaako Tween 20 myös 2,4,5-TP:n tehoa omenien putoamisen vähentämisessä. Paineruiskulla ruiskutettaessa sisälsi ruiskutusneste $0.125 \%$ Tween 20 ja sumuruiskua käytettäessä $0.25 \%$.

\section{Koetulokset ja niiden tarkastelu}

Koetulokset on esitetty taulukoissa 1 ja 2 sekä kuvissa 1 ja 2 .

Bergius-, Sävstaholm-, Melba- ja Atlas-lajikkeiden osalta on 20 ppm:n 2,4,5TP-liuos yhdessä $0.125 \%$ Tween $20: n$ kanssa erittäin tehokkaasti vähentänyt omenien putoamista (taulukko 1). Nämä koepuut eivät joutuneet koeaikana alttiiksi kovien tuulien vaikutukselle. Suurin tuulen nopeus oli $6 \mathrm{~m} / \mathrm{sek}$. Ruiskutuksen teho olisi ilmeisesti näiden lajikkeiden kohdalla säilynyt pitemmänkin aikaa kuin 21 ja 24 päivää. Tämä ilmenikin selvästi Bergius-lajikkeella, jonka omenien putoamista seurattiin jättämällä kahden rinnakkain kasvavan puun — toinen ruiskutettu, toinen kontrollipuu — satojen korjuu yksitoista päivää myöhemmäksi kuin muiden koepuiden. Tällöin 32 päivän kuluttua ruiskutuksesta oli ruiskuttamatta jätetty puu pudottanut $26.5 \%$ omenistaan, kun sitä vastoin ruiskutuksen saaneessa puussa oli pudonneiden omenien määrä vain $2.0 \%$ sadosta. Putoamista ei näiden puiden osalta voitu kuitenkaan seurata pitemmälle, koska niiden omenat alkoivat ylikypsymisestä johtuen halkeilla.

Wealthy-, Åkerö- ja Antonovka-puiden ruiskutuksessa seurattiin 2,4,5-TP:n vaikutusta yksinään sekä myös yhdistettynä Tween 20:n kanssa (taulukko 2, kuvat 1 ja 2). Samalla verrattiin toisiinsa paine- ja sumuruiskun vaikutusta, jolloin sumuruiskulla annettu liuos oli 2,4,5-TP:n osalta neljä kertaa ja Tween 20:n osalta kaksi kertaa väkevämpää kuin paineruiskua käytettäessä. Wealthy- ja Åkeröpuita koskeva koe suoritettiin Spurilan hedelmätarhassa Paimiossa. Antonovkapuut kasvoivat Puutarhantutkimuslaitoksen hedelmätarhassa.

Kolmen mainitun lajikkeen osalta ovat erot pudonneiden omenien määrissä muodostuneet erittäin selviksi ruiskutettujen ja käsittelemättömien puiden välillä (taulukko 2). Erityisesti Spurilan hedelmätarhassa vaikutti tuloksiin $1-2 / 10$ 
(19-20 päivän kuluttua käsittelystä) vallinnut voimakas tuuli, jonka nopeudeksi todettiin Piikkiön säähavaintopaikassa $8-10 \mathrm{~m} / \mathrm{sek}$. Vaikka tuuli tämän jälkeen tyyntyikin huomattavasti, putosi neljän seuraavan päivän aikana käsittelemättömien Wealthy- ja Åkerö-puiden omenista keskimäärin 41 ja 46 prosenttia. Mainittakoon, että ko. hedelmätarhassa oli kokeiden ulkopuolella olevien Åkeröomenien korjuu tässä vaiheessa vielä kokonaan suorittamatta. Wealthy-lajikkeen korjuu oli käynnissä. Sen sijaan Antonovka-lajikkeeseen ei mainitulla tuulella ollut niin tuhoisia seurauksia, osaksi sen vuoksi, että Puutarhantutkimuslaitoksen hedelmätarha oli tältä tuulelta paljon suojatumpi kuin Spurilan hedelmätarha, ja osaksi sen vuoksi, että Antonovka-omenat eivät vielä olleet saavuttaneet samaa kypsyysastetta kuin Wealthy- ja Åkerö-lajikkeet.

Taulukko 1. 2,4,5-triklorfenoksipropionihapon (2,4,5-TP) vaikutus omenien putoamiseen ennen sadonkorjuuta.

Table 1. The effect of 2,4,5-trichlorophenoxypropionic acid $(2,4,5-T P)$ on the preharvest drop of apples.

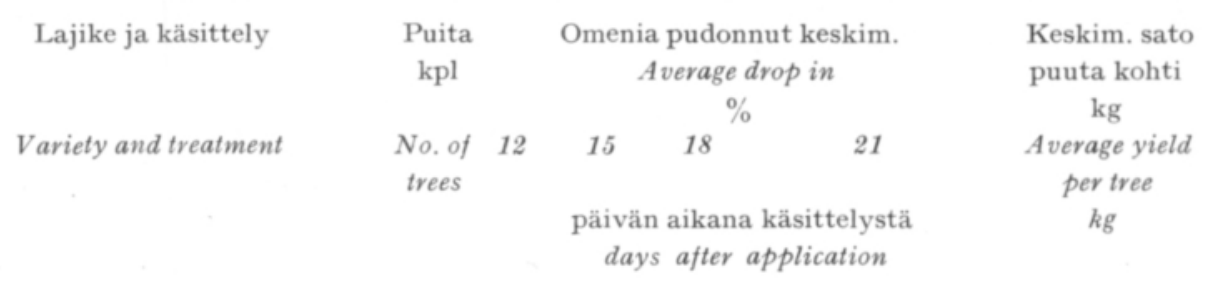

Bergius

Käsittely 21 pv ennen korj.

Application 21 days before harvest

$\begin{array}{lrrrrrr}20 \text { ppm 2,4,5-TP }+0.125 \% \text { Tween } 20 & 5 & 0.1 & 0.1 & 0.1 & 0.2 \pm 0.05 & 61.6 \\ \text { Käsittelemätön - Check } & 5 & 1.8 & 3.7 & 6.0 & 13.3 \pm 3.8 & 53.8\end{array}$

Sävsta $h$ ol $m$

Käsittely 21 pv ennen korj.

Application 21 days before harvest

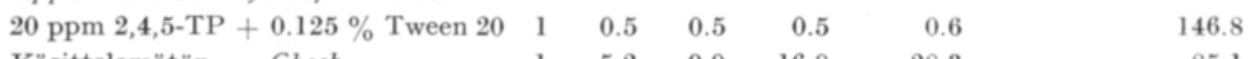

$\begin{array}{lllllllr}\text { Käsittelemätön }- \text { Check } & 1 & 5.2 & 9.0 & 16.8 & 28.3 & 85.1\end{array}$

$M$ e l b a

Käsittely 21 pv ennen korj.

Application 21 days before harvest

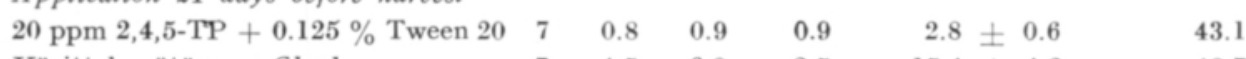

Käsittelemätön - Check

$7 \quad 4.5$

$6.0 \quad 8.5$

$15.4 \pm 4.2$

48.7

\section{At l a s}

Käsittely 24 pv ennen korj.

Application 24 days before harvest

20 ppm 2,4,5-TP $+0.125 \%$ Tween 20

Käsittelemätön - Check $\begin{array}{llll}10 & 15 & 21 & 24\end{array}$ päivän aikana käsittelystä days after application

$\begin{array}{llll}0 & 0.1 & 0.3 & 0.5\end{array}$

$\begin{array}{llll}0.9 & 1.5 & 6.3 & 26.9\end{array}$ 
Taulukko 2. 2,4,5-triklorfenoksipropionihapon (2,4,5-TP) vaikutus omenien putoamiseen ennen sadonkorjuuta.

Table 2. The effectiveness of 2,4,5-trichlorophenoxypropionic acid $(2,4,5-T P)$ in controlling the preharvest drop of apples.

Lajike ja käsittely

Variety and treatment
Ruisku

Paineruisku

Dilute

$$
\text { - - - }
$$

Sumuruisku

Concentrate

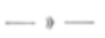

80 ppm 2,4,5-TP $+0.25 \%$ Tween 20

Käsittelemätön - Check

A kerö

Käsittely $24 \mathrm{pv}$ ennen korjuuta

Application 24 days before harvest

20 ppm 2,4,5-TP

20 ppm 2,4,5-TP $+0.125 \%$ Tween 20

Käsittelemätön - Check

\section{A n to novk}

Käsittely 33 pv ennen korjuuta

Application 33 days before harvest

$20 \mathrm{ppm} 2,4,5$-TP

20 ppm 2,4,5-TP $+0.125 \%$ Tween 20

80 ppm 2,4,5-TP

80 ppm 2,4,5-TP $+0.25 \%$ Tween 20 Käsittelemätön - Check

Dilute

Sumuruisku
Concentrate

Puita Omenia pudonnut keskim. Keskim. Average drop in

sato

puuta kohti

kpl $\quad \% \quad$ kg

$20 \quad 24$

No. päivän aikana käsittelystä Average of trees days after application yield per tree $\mathrm{kg}$

6

6

F-arvo

10.6
5.4
4.4

18.6

8.4

71.0

6

4.4

9.1

62.6

65.5

53.5

25.8

4.2

70.4

\begin{tabular}{lccc}
$\begin{array}{l}\text { Paineruisku } \\
\text { Dilute }\end{array}$ & 6 & 2.9 & 5.0 \\
\hdashline- & 6 & 2.5 & 3.9 \\
& 6 & 31.8 & 77.5 \\
& F-arvo (sarakk. 24 pv.) \\
& & $252.3^{\text {t** }}$ \\
& F-value (column 24 days) \\
& Merkitsevä ero $11.8 \%$ \\
& Sign. diff.
\end{tabular}

31

päivän aikana käsittelystä days after application

Paineruisku 5

$6.2 \quad 6.9$ 73.7

0.8

0.8

60.5

1.2

1.4

68.7

0.9

0.9

39.6

10.7

17.2

F-arvo (sarakk. 34 pv)

64.2 


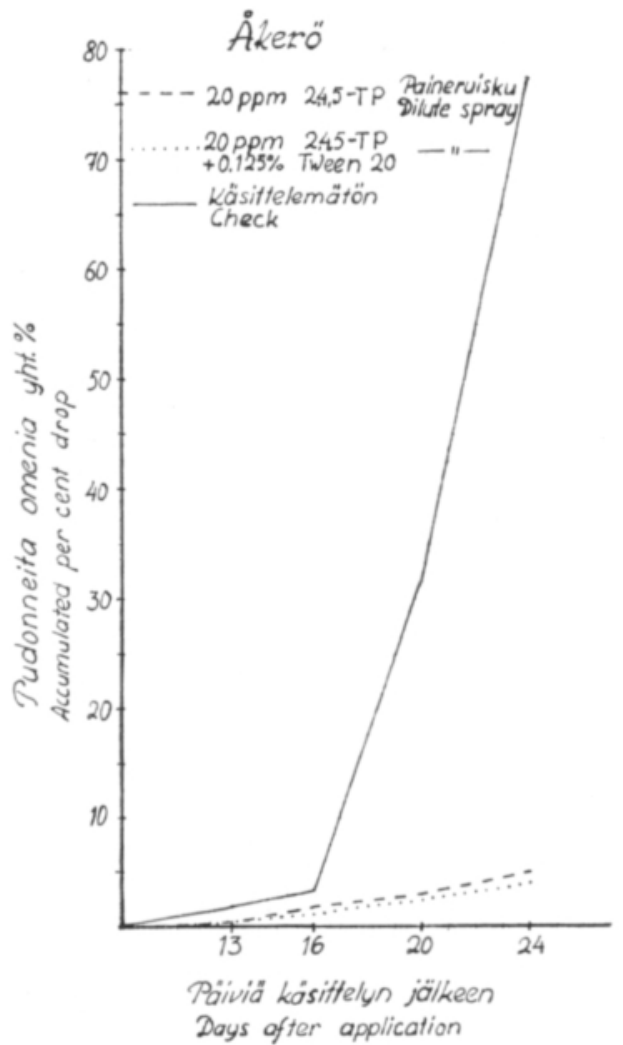

Kuva 1. 2, 4, 5-TP:n vaikutus Ákerö-omenien putoamiseen.

Fig. 1. The effect of 2, 4, 5-TP in delaying drop of Akerö apples.

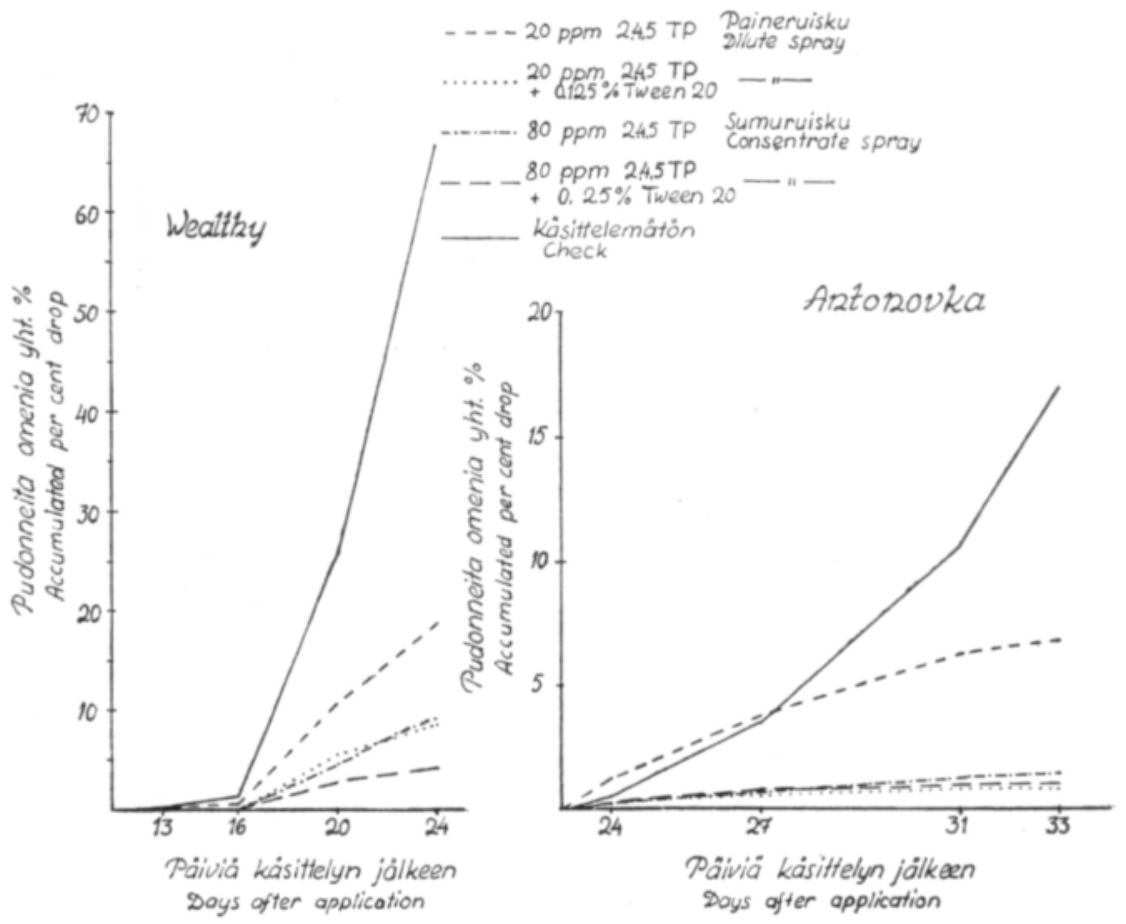

Kuva 2. 2, 4, 5-TP:n vaikutus Wealthy- ja Antonovka-omenien putoamiseen.

Fig. 2. The effect of 2, 4, 5-TP in delaying drop of Wealthy and Antonovka apples. 
Tarkasteltaessa Tween 20:n vaikutusta yhdessä 2,4,5-TP:n kanssa voidaan havaita, että se on jonkin verran parantanut 2,4,5-TP:n tehoa (taulukko 2). Wealthylajikkeessa on tämä vaikutus paineruiskua käytettäessä jäänyt merkitsevyyden rajalle, mutta sen sijaan Antonovka-lajikkeessa on ero tässä suhteessa muodostunut selväksi. Poikkeuksena on kuitenkin Åkerö-lajike, jossa 20 ppm 2,4,5-TP-liuos ilman Tween 20:a on antanut suunnilleen yhtä hyvän tuloksen kuin yhdessä Tween 20:n kanssa käytettynä. Ilmeisesti tämä osaltaan johtuu Åkerö-lajikkeen herkkyydestä ns. kasvuaineiden vaikutukselle. Niinpä esimerkiksi $\alpha$-naftyylietikkahappo ei sovi Åkerön raakileiden harventamiseen. Tämän aineen hyvin alhaisetkin väkevyydet (5-10 ppm) aiheuttavat Åkerön-raakileiden liikaharvennusta sekä kannuslehtien vioittumista ja surkastumista (Puutarhantutkimuslaitoksen vielä julkaisemattomat kokeet).

Sumuruiskun sekä neljä kertaa suuremman väkevyyden $(80 \mathrm{ppm})$ käyttäminen on antanut paremman tuloksen verrattuna paineruiskulla tehtyyn käsittelyyn. Tномpson (12) mainitsee, että sumuruiskukäsittelyssä on 80 ppm:n 2,4,5-TP-liuos ollut liian voimakastehoinen Gallia Beauty-lajikkeeseen, jolloin omenien poimiminen on vaikeutunut. Tällaista vaikutusta ei sillä näissä kokeissa todettu olevan ainakaan Wealthy- ja Antonovka-lajikkeisiin. Nelinkertaisen väkevyyden käytöstä huolimatta jäi 2,4,5-TP:n kulutus sumuruiskukäsittelyssä n. $50 \%$ pienemmäksi kuin paineruiskulla ruiskutettaessa.

2,4,5-TP-ruiskutus paransi kaikkien kokeiltavina olleiden lajikkeiden väriä. Erityisen edullinen oli sen vaikutus Atlas- ja Melba-omenien väriin. Käsiteltyjen Antonovka-omenien väri oli korjuuvaiheessa kauniin keltainen.

Edellä esitetyt kokeet osoittivat, että 2,4,5-TP:a käyttäen voidaan omenien putoamista ennen sadonkorjuuta tehokkaasti vähentää. Paitsi ennen sadonkorjuuta, vähentää sen käyttö omenien putoamista myös korjuutyön aikana, mikä muutamilla lajikkeilla (esim. Wealthy) on yleistä. Aineen käytöllä saavutetaan myös edullinen vaikutus omenien laatuun, ei vain voimakkaan värittymisen vuoksi, vaan myös siitä syystä, että omenien voidaan ilman suurempaa putoamisvaaraa antaa tuleentua puussa oikeaan korjuukypsyyteen. Useinhan tapahtuu, että viljelijät korjaavat omenat putoamistappioita peläten liian aikaisin, josta johtuen niiden laatu kärsii. 2,4,5-TP-ruiskutus tulisi kuitenkin suorittaa vain n. kaksi-kolme viikkoa ennen arvioitua korjuupäivää. Liian aikaisin tehty ruiskutus voi haitallisessa määrin edistää kesäomenien kypsymistä. Käytettäessä sitä kesäomenalajikkeilla on myös varottava korjuun siirtämistä liian pitkälle, koska on olemassa vaara, että omenien säilyminen liian pitkälle edistyneestä kypsymisestä heikkenee. Tulokset ovat kuitenkin riippuvaisia paljon siitä, miten huolellisesti ruiskutustyö suoritetaan. Ruiskutusnestettä on yleensä käytettävä runsaammin kuin tavallisissa kasvinsuojeluruiskutuksissa. Ruiskutusnestettä tarvitaan 10-12-vuotiasta puuta kohti paineruiskua käytettäessä 8-10 1. Sumuruiskua käytettäessä on vastaava ruiskutusnesteen tarve n. 1.5 l. Sumuruiskun käyttö tarjoaa myös suuren edun työn säästön kannalta verrattuna paineruiskuun.

Tween 20:n vaikutus 2,4,5-TP:en on ilmeisesti samanlainen kuin sen vaikutus $\alpha$-naftyylietikkahappoon. HARLEY ym. (7) totesivat sen lisäävän viimeksi mainitun aineen imeytymistä kannuslehtiin. Tween 20:n yhdistämistä 2,4,5-TP:en on 
käytännössä kuitenkin syytä välttää siksi, kunnes sen vaikutuksesta omenien makuun ja säilyväisyyteen on saatu riittävästi selvyyttä.

\section{Yhteenveto}

Edellä on selvitetty 2,4,5-triklorfenoksipropionihapon $(2,4,5$-TP) vaikutusta omenien putoamisen vähentämiseksi ennen sadonkorjuuta ja sen aikana. Ainetta kokeiltiin lajikkeilla Bergius, Sävstaholm, Melba, Atlas, Wealthy, Åkerö ja Antonovka. Käsittely suoritettiin $21-33$ päivää ennen sadonkorjuuta. Kokeissa selvitettiin myös Tween 20-valmisteen (polyoksietyleeni sorbitan monolauraatin) vaikutusta 2,4,5-TP:n tehoon. Edelleen verrattiin toisiinsa paineruiskun ja sumuruiskun käyttöä 2,4,5-TP-käsittelyssä. Kokeista saadut tulokset on esitetty taulukoissa 1 ja 2 sekä kuvissa 1 ja 2.

2,4,5-TP on tehokkaasti vähentänyt omenien putoamista kaikista kokeiltavina olleista lajikkeista. Sillä on ollut verrattain pitkäaikainen vaikutus.

Tween 20:n yhdistäminen 2,4,5-TP:en on parantanut viimeksi mainitun tehoa.

Käytettäessä ruiskutukseen sumuruiskua ja $80 \mathrm{ppm}: n$ väkevyyttä on saatu parempi tulos kuin paineruiskua ja 20 ppm:n väkevyyttä käyttäen. Sumuruiskulla ruiskutettaessa on 2,4,5-TP:ä käytetty n. $50 \%$ vähemmän puuta kohti verrattuna paineruiskulla suoritettuun käsittelyyn.

2,4,5-TP on parantanut kaikkien kokeissa olleiden lajikkeiden omenien väriä.

K I R J A L L I S U U T T A

(1) Batjer, L. P. \& Thompson, A. H. 1946. Effects of 2,4-dichlorophenoxyacetic acid sprays in controlling the harvest drop of several apple varieties. Proc. Amer. Soc. Hort. Sci. 47: 35-38. (Ref. Hort. Abst. 17: 70).

(2) —- 1947: Further studies with 2,4-dichlorophenoxyacetic acid sprays in retarding fruit drop of Winesap apples. Ibid. 49: 45-48.

(3) Blair, D. S. \& Nelson, S. H. 1955. Reduction of pre-harvest and harvest drop in apples by spraying with growth regulating substances. Progr. Rep. Div. Hort. Centr. Exp. Farm Ottawa $1949-53$, p. $44-49$.

(4) Edgerton, L. J. \& Hoffman, M. B. 1951. The effectiveness of several growth regulating chemicals in delaying the harvest drop of the McIntosh apple. Proc. Amer. Soc. Hort. Sci. 57: 120 124.

(5) Erickson, L. C. \& Brannaman, B. L. \& Hield, H. Z. 1952. Response of Delícious and Rome Beauty apples to a preharvest spray of 2,4,5-trichlorophenoxypropionic acid in Southern California. Ibid. 60: 160-164.

(6) Gardner, F. E. \& Marth, P. C. \& Batjer, L. P. 1939. Spraying with plant growth substances to prevent apple fruit dropping. Science 90: 208-209.

(7) Harley, C. P. \& Moon, H. H. \& Regeimbal, L. O. 1957. Effects of the additive Tween 20 and relatively low temperatures on apple thinning by naphthaleneacetic acid sprays. Proc. Amer. Soc. Hort. Sci. 69: 21-27.

(8) Luckwill, L. C. 1952. The mechanism of fruit drop in pome fruits and its control by synthetic growth-substances. Rep. 13th Intern. Hort. Congr. p. 223-229, London. 
(9) Matrus, G. E. \& Moore, R. C. 1954. Preharvest growth regulator sprays on apples. I Drop and maturity 1952 and 1953. Proc. Amer. Soc. Hort. Sci. 64: 199-208.

(10) Southwick, F. W. \& Demoranville, I. E. \& Anderson, J. F. 1953. The influence of some growth regulating substances on preharvest drop, color and maturity of apples. Ibid. 61: $155-162$.

(11) Tномpson, A. H. 1951. The effect of 2,4,5-trichlorophenoxypropionic acid sprays in delaying the preharvest drop of several apple varieties. Ibid. 58: $57-64$.

(12) $\rightarrow$ 1952. Further experiments with 2,4,5-trichlorophenoxypropionic acid sprays for control of the preharvest drop of apples. Ibid. 60: 175-183.

S U M M A R Y :

ON THE PREHARVEST AND HARVEST DROP OF APPLES

ЈААККо SӒКӦ

Agricultural Research Centre, Department of Horticulture, Piikkiö

The preharvest and harvest drop of apples often causes considerable losses to the fruit growers. The early summer varieties are especially liable to drop, but dropping is also found to be a common occurrence among many autumn and certain winter varieties. In a few varieties, such as Filippa, the fall may be quite rapid. In most varieties, however, it happens graduelly increasing during the time the apples approach their full maturity. On the other hand we also know apple varieties, which keep their fruits well after reaching maturity. This is the case e.g. with Huvitus and Lobo, which are grown as standard varieties in Finland.

Spraying with growth regulating substances in order to delay the preharvest drop of apples has been a common practice especially in the USA and Canada. The chemical first used for this purpose was $\alpha$-naphthaleneacetic acid. However, in this respect great progress was made when EDGERTON and Hoffman (4) found that 2,4,5-trichlorophenoxypropionic acid (2,4,5-TP) was an ideal chemical for the control of the preharvest drop of McIntosh apples. Later such sprays have been applied succesfully to several apple varieties $(3,5,10,11,12)$.

In 1958 experiments for controlling the preharvest and harvest drops of some apple varieties with 2,4,5-TP were made at the Department of Horticulture, Piikkiö. The following varieties were tested: Bergius, Sävstaholm, Melba, Atlas, Wealthy, Åkerö and Antonovka. The applications were given $21-33$ days before the harvest, both by dilute $(20 \mathrm{ppm})$ and by concentrate $(80 \mathrm{ppm})$ sprays. Furthermore the effect of Tween 20 (polyoxyethylene sorbitan monolaurate) on 2,4,5-TP was studied. Tween 20 has been used as an additive to increase the effect of $\alpha$-naphthaleneacetic acid in the thinning of apples (7).

The results are shown in Tables 1 and 2, and in Figs. 1 and 2.

2,4,5-TP has proved very effective in delaying preharvest and harvest drops in all the varieties mentioned here. The concentraded sprays $(80 \mathrm{ppm})$ have been superior to the diluted (20 ppm) applications. A concentration of $80 \mathrm{ppm}$ did not result in picking difficulties at harvest. Despite the higher concentration, the low volume application supplied only about 50 per cent of the $2,4,5$-TP applied per tree in the dilute spray.

The additive Tween 20 in concentrations of 0.125 and 0.25 per cent increased the effect of 2,4,5-TP in the Wealthy and Antonovka varieties, whereas on the Åkerö variety it did not have any marked effect.

In all the varieties mentioned the application of 2,4,5-TP resulted in a better colour of the apples. This was particularly pronounced in the Melba and Atlas apples. The treated Antonovka apples were also decidedly more yellow at harvest time than the apples from the check trees. 